\title{
Porous poly(L-lactic acid)/apatite composites created by biomimetic process
}

\author{
Ruiyun Zhang, Peter X. Ma \\ Departments of Biologic and Materials Sciences and Biomedical Engineering, Macromolecular Science and Engineering \\ Center, 1011 North University Avenue, The University of Michigan, Ann Arbor, Michigan 48109-1078
}

Received 1 April 1998; accepted 4 November 1998

\begin{abstract}
Highly porous poly(L-lactic acid)/apatite composites were prepared through in situ formation of carbonated apatite onto poly(L-lactic acid) foams in a simulated body fluid. The highly porous polymer foams (up to $95 \%$ porosity) were prepared from polymer solution by solidliquid phase separation and subsequent sublimation of the solvent. The foams were then immersed in the simulated body fluid at $37^{\circ} \mathrm{C}$ to allow the in situ apatite formation. After incubation in the simulated body fluid for a certain period of time, a large number of characteristic microparticles formed on the surfaces of pore walls throughout the polymer foams. The microparticles were characterized with scanning electron microscopy, energy dispersive spectroscopy, Fourier transform IR spectroscopy, and X-ray diffrac-
\end{abstract}

tometry. These porous spherical microparticles were assemblies of microflakes. They were found to be carbonated bonelike apatite. A series of composite foams with varying sizes and concentrations of the apatite particles was obtained by varying incubation time and conditions. These porous composites may be promising scaffolding materials for bone tissue engineering and regeneration because the excellent bone-bonding properties of the apatite may provide a good environment for osteoblast and osteoprogenitor cells' attachment and growth. (C) 1999 John Wiley \& Sons, Inc. J Biomed Mater Res, 45, 285-293, 1999.

Key words: composite; polymer; scaffold; foam; hydroxyapatite

\section{INTRODUCTION}

Bone fractures and damage are serious health problems, which result in more than 1.3 million surgical procedures each year in the United States. ${ }^{1}$ The current bone repairing or replacing materials include autografts, allografts, and various kinds of manmade materials such as polymers, bioceramics, metallic materials, and their composites. However, none of them is a perfect solution. Tissue engineering offers a promising new approach to bone repair. ${ }^{2-5}$ In this approach, a porous scaffold is needed to guide cell attachment, growth, and tissue regeneration in 3 dimensions. ${ }^{6-9}$

There are several basic requirements for scaffolding materials. They should be biocompatible and biodegradable. The degradation products should be nontoxic and easily excreted by metabolic pathways. The materials should be easy to fabricate into a desired shape and have a controlled pore architecture to allow for cell infiltration, attachment, growth, tissue regen-

Correspondence to: Prof. Peter X. Ma; e-mail: mapx@ umich.edu

(C) 1999 John Wiley \& Sons, Inc.

CCC 0021-9304/99/040285-09 eration, and vascularization. The scaffolds should be mechanically stable to keep their structural integrity during the tissue regeneration. The scaffolding materials for bone tissue engineering should also be osteoconductive, so that osteoblasts and osteoprogenitor cells will attach and migrate on the scaffolds. The poly $(\alpha$-hydroxyl acids) such as poly(lactic acid) (PLA), poly(glycolic acid) (PGA), and poly(lactic acid-coglycolic acid) (PLGA) satisfy many of these material requirements and have been fabricated into scaffolds for cell transplantation and tissue engineering. ${ }^{5-11}$

Various bioactive ceramics such as sintered hydroxyapatite $(\mathrm{HA})^{12}$ and glass-ceramic apatite-wollastonite $(\mathrm{A}-\mathrm{W})^{13}$ were developed and clinically used as bone repairing and replacing materials. These bioactive ceramics were found to bond to bone through a layer of bonelike apatite formed on the surface of the ceramics in the body and were characterized as carbonate-containing HAs with small crystallites and a defective structure. ${ }^{14-17}$ The apatite was not observed at the interface between nonbioactive materials and bone. ${ }^{15,17}$ Therefore, it is believed that the bonelike apatite layer plays a key role for bone bonding to these bioactive ceramics.

Some polymer materials such as Polyactive ${ }^{\circledR}$ (ethyl- 
ene oxide-butylene terephthalate copolymer) were reported to have the ability to bond to bone. ${ }^{18}$ On the surface of these solid polymers, the formation of bonelike apatite was also observed after being implanted in bone. ${ }^{19}$ Highly porous poly ( $\alpha$-hydroxy acids)/HA composites were developed previously in our lab. ${ }^{5}$ In this work, highly porous poly(L-lactic acid) (PLLA) foams were prepared by solid-liquid phase separation of the polymer solution and subsequent sublimation of the solvent. The bonelike apatite was grown on the surfaces of pore walls throughout the PLLA foams in a simulated body fluid (SBF). The highly porous biodegradable polymer/apatite composites were created as a new type of composite scaffold for bone tissue engineering.

\section{MATERIALS AND METHODS}

PLLA with an inherent viscosity of approximately 1.6 was purchased from Boehringer Ingelheim (Ingelheim, Germany). There were no free carboxyl end groups on the PLLA. Dioxane, chloroform, sodium chloride, calcium chloride, sodium hydrogencarbonate, potassium chloride, potassium phosphate, magnesium chloride hexahydrate, sodium sulfate, potassium bromide (for IR spectral specimen preparation), and synthetic $\mathrm{HA}\left[3 \mathrm{Ca}_{3}\left(\mathrm{PO}_{4}\right)_{2} \cdot \mathrm{Ca}(\mathrm{OH})_{2}\right]$ were purchased from Aldrich (Milwaukee, WI).

\section{Polymer foams and films}

The polymer foams were prepared by solid-liquid phase separation of polymer solutions and subsequent sublimation of solvent as reported earlier. ${ }^{5}$ The polymer was dissolved in dioxane to make a solution of a desired concentration (from 2.5 to $7.5 \%)$. The polymer solution $(10 \mathrm{~mL})$ was transferred into a beaker $(30 \mathrm{~mL})$, then the beaker was rapidly transferred into a refrigerator or a freezer at a present temperature to solidify the solvent and induce solid-liquid phase separation. The solidified solution was maintained at that temperature for $2 \mathrm{~h}$ and then immersed in liquid nitrogen to deep freeze. The frozen mixture was transferred into a freeze-drying vessel at -5 to $-10^{\circ} \mathrm{C}$ in an ice/salt bath and then freeze-dried at $0.5 \mathrm{mmHg}$ for 7 days to completely remove the solvent. Ninety-nine percent of the solvent was removed in 1 day, and a constant sample weight was achieved within 4 days. The foam samples were stored in a desiccator until incubation or characterization.

Solid PLLA films were cast from a 5\% PLLA/chloroform solution on a glass plate at room temperature. Rectangular specimens with dimensions of $30 \mathrm{~mm} \times 10 \mathrm{~mm} \times 40 \mu \mathrm{m}$ were obtained.

\section{SBF}

An SBF with a modified formulation of the earlier SBF proposed by Kokubo et al. ${ }^{20}$ was prepared by dissolving reagent grade chemicals of $\mathrm{NaCl}, \mathrm{NaHCO}_{3}, \mathrm{KCl}$, $\mathrm{K}_{2} \mathrm{HPO}_{4} \cdot 3 \mathrm{H}_{2} \mathrm{O}, \mathrm{MgCl}_{2} \cdot 6 \mathrm{H}_{2} \mathrm{O}, \mathrm{CaCl}_{2}$, and $\mathrm{Na}_{2} \mathrm{SO}_{4}$ in deionized water. The inorganic ion concentrations $\left(\mathrm{mM} ; \mathrm{Na}^{+}\right.$ 213, $\mathrm{K}^{+} 7.5, \mathrm{Mg}^{2+}$ 2.3, $\mathrm{Ca}^{2+} 3.8, \mathrm{Cl}^{-} 223, \mathrm{HCO}_{3}{ }^{-} 27, \mathrm{HPO}_{4}{ }^{2-}$ $1.5, \mathrm{SO}_{4}{ }^{2-} 0.8$ ) were 1.5 times those of human blood plasma. The fluid was buffered at a $\mathrm{pH}$ value of 7.4 at $37^{\circ} \mathrm{C}$ with tris-(hydroxymethyl) aminomethane $\left[\left(\mathrm{CH}_{2} \mathrm{OH}\right)_{3} \mathrm{CNH}_{2}\right]$ and hydrochloric acid $(\mathrm{HCl})$. The solution was metastable and does not precipitate calcium phosphate without external stimulation.

\section{PLLA incubation in SBF}

Five rectangular polymer foam specimens with dimensions of $12 \times 8 \times 6 \mathrm{~mm}$ were immersed in $100 \mathrm{~mL} \mathrm{SBF}$ in a glass bottle maintained at $37^{\circ} \mathrm{C}$. A series of brief evacuationrepressurization cycles was performed to force the solution into the pores of the foams. Cycling was continued until there were no air bubbles emerging from the foams. The SBF was renewed every other day. After being incubated for various periods of time, the specimens were removed from the fluid and immersed overnight in $100 \mathrm{~mL}$ deionized water to remove the soluble inorganic ions. The solid PLLA films (30 mm $\times 10 \mathrm{~mm} \times 40 \mu \mathrm{m}$ ) were treated with the same process in the SBF (five films in $100 \mathrm{~mL} \mathrm{SBF}$ ).

\section{Characterizations}

The porosity was determined with a liquid displacement method reported in detail earlier. ${ }^{5}$ Ethanol was chosen as the displacement liquid because it penetrated easily into the pores and did not induce shrinkage or swelling as a nonsolvent of the polymers. A foam sample of weight $W$ was immersed in a graduated cylinder containing a known volume $\left(V_{1}\right)$ of ethanol. The sample was kept in the ethanol for 5 min, and then a series of brief evacuation-repressurization cycles was conducted to force the ethanol into the pores of the foam. Cycling was continued until no air bubbles emerged from the foam. The total volume of ethanol and the ethanol-impregnated foam was then recorded as $V_{2}$. The volume difference, $\left(V_{2}-V_{1}\right)$, was the volume of the polymer/apatite composite skeleton of the foam. The ethanolimpregnated foam was removed from the cylinder, and then the residual ethanol volume was recorded as $V_{3}$. The quantity $\left(V_{1}-V_{3}\right)$, the volume of the ethanol held in the foam, was determined as the void volume of the foam; thus, the total volume of the foam was

$$
V=\left(V_{2}-V_{1}\right)+\left(V_{1}-V_{3}\right)=V_{2}-V_{3} .
$$

The density of the foam, $d$, was expressed as

$$
d=W /\left(V_{2}-V_{3}\right)
$$

and the porosity of the foam, $\varepsilon$, was obtained by

$$
\varepsilon=\left(V_{1}-V_{3}\right) /\left(V_{2}-V_{3}\right) .
$$

The morphology of the incubated polymer foams and films was studied by scanning electron microscopy (SEM; S-3200N, Hitachi, Japan) at $15 \mathrm{kV}$. All SEM micrographs 
shown in this article were taken from foams prepared from a 5\% PLLA solution. The specimens were cut into halves with a razor blade, and the exposed new surfaces were observed with SEM. For microstructural observation, the specimens were coated with gold using a sputter coater (Desk-II, Denton Vacuum Inc.). The gas pressure was less than 50 mTorr and the current was about $40 \mathrm{~mA}$. The coating time was 200 s. Energy-dispersive spectroscopy (EDS) was also used to obtain information on the elementary composition of the particles grown from SBF incubation. For EDS analysis, the specimens were not coated and the environmental mode was used.

Fourier transform IR (FTIR) spectra were obtained with a Nicolet 5-DX FTIR spectrometer with a resolution of $4 \mathrm{~cm}^{-1}$. A small amount of powder was scratched from the surface of an incubated polymer foam or film, then it was milled with $\mathrm{KBr}$ and pressed into a transparent film for IR analysis. The IR spectrum of the HA was obtained from a commercial synthetic HA powder from Aldrich.

The X-ray diffraction (XRD) spectra were obtained with a Rigaku rotating-anode $\mathrm{X}$-ray diffractometer (Rotaflex) at a $2 \theta$ scan rate of $2.5^{\circ} / \mathrm{min}$. $\mathrm{Cu} \mathrm{K} \alpha$ ratiation was used for the diffraction with a voltage of $40 \mathrm{kV}$ and a current of $100 \mathrm{~mA}$.

The mass increase of the foams during the apatite formation in the SBF was measured with an analytical balance accurate to $10^{-4} \mathrm{~g}$. The PLLA foams and the PLLA/apatite composite foams were dried in a fume hood for 1 week and then vacuum dried at $0.5 \mathrm{mmHg}$ for $24 \mathrm{~h}$ before measuring. The percentage mass increase was normalized with the foams incubated in a Tris buffer at the same $\mathrm{pH}$ (7.4), the same temperature $\left(37^{\circ} \mathrm{C}\right)$, and for the same time intervals (control samples). Six specimens were measured for each sample to obtain the averages and standard deviations. The apatite particle diameter and number density were obtained from the SEM micrographs of the composite foams. The micrographs were taken from the typical internal surfaces that were oriented horizontally. The SEM micrographs were divided into equal rectangular areas. For each sample, 10 of these areas that were continuous and horizontally oriented were selected to calculate the particle density per unit area (number $/ 100 \mathrm{\mu m}^{2}$ ). For each sample, 60 particles were measured to calculate the average diameter and standard deviation.

The compressive mechanical testing was conducted with an Instron 4502 mechanical tester (Instron Co., Canton, MA). The specimens were circular disks with the same geometry as a different type of composite sample used previously ( 16 $\mathrm{mm}$ in diameter and $\sim 3 \mathrm{~mm}$ in thickness)..$^{5}$ The crosshead speed was $0.5 \mathrm{~mm} / \mathrm{min}$. The compressive modulus was defined as the initial linear modulus. Six specimens were tested for each sample. The averages and standard deviations were graphed.

A two-tail Student's $t$ test (assuming equal variances) was performed to determine the statistical significance $(p<0.05)$ of the differences in particle size, density, mass change, and foam mechanical properties.

\section{RESULTS}

The PLLA foams prepared from solid-liquid phase separation of the PLLA/dioxane solutions were highly porous and had an open pore structure [Fig. 1(a)]. A porosity of up to $95 \%$ was achieved by this procedure. The porosity of the foam prepared from a $5 \%$ PLLA solution was $92.7 \%$. An anisotropic tubular morphology with an internal ladderlike structure was obtained. The channels were parallel to the direction of solidification (heat transfer direction). Each channel had repeating partitions with uniform spacing perpendicular to the solidification direction. The diameter of the channels and the spacing between repeating partitions in the channels ranging from several tens of microns to several hundred microns were controlled by varying the cooling rate and the concentration of the polymer solution. This characteristic morphology was attributed to the crystallization of the solvent during solid-liquid phase separation. ${ }^{5}$

The PLLA foams were immersed in the SBF at $37^{\circ} \mathrm{C}$ to grow apatite. After 30 days, a large number of microparticles with a diameter up to $2 \mu \mathrm{m}$ was formed on the surfaces of the PLLA pore walls (Fig. 1). The particles were assembled with small flakelike pieces. Others observed similar morphology of carbonated HA formed on a silica gel surface after incubating in SBF. ${ }^{16}$ The EDS spectrum showed that the main elements of the incubated PLLA foam were carbon, oxygen, calcium, and phosphorus [Fig. 2(a)]. Carbon and oxygen could be from both PLLA and the particles, but calcium and phosphorus could only be from the particles. These results suggested that the particles formed in the PLLA foams might be similar to HA. Microparticles were also formed on the solid PLLA films treated in SBF under the same conditions (Fig. 3). The particles on the PLLA films were larger than those in the PLLA foams. The surfaces of the films were completely covered with the microparticles after 15 days of incubation [Fig. 3(a)]. The morphology of the formed particles was also a flakelike assembly [Fig. 3(b)]. EDS analysis indicated that calcium and phosphorus were also the main elements in the particles [Fig. 2(b)].

Wide-angle XRD was used to characterize the porous composites. The two strong characteristic peaks of $\mathrm{HA}^{21}$ were shown from the apatite powder obtained from the surface of PLLA films incubated in the SBF [Fig. 4(a)]. The composite foams [Fig. 4(b, c)] showed the characteristic peaks of apatites [compare to Fig. 4(a)] and the characteristic peaks of PLLA ${ }^{22}$ [compare to Fig. 4(d)]. The amplitudes of apatite peaks increased with incubation time in the SBF (in comparison to PLLA peaks).

FTIR spectroscopy was used to gain more information on the microparticles formed in the PLLA foams and on the PLLA films. The spectra of the formed particles were similar to that of a commercial synthetic HA (Fig. 5). The characteristic absorption bands of phosphate in HA appearing at 565, 604, 962, and 1085 $\mathrm{cm}^{-1}$, which reflect the phosphate vibration mode of $v_{4}, v_{1}$, and $v_{3}$, respectively, ${ }^{23,24}$ were observed for all 


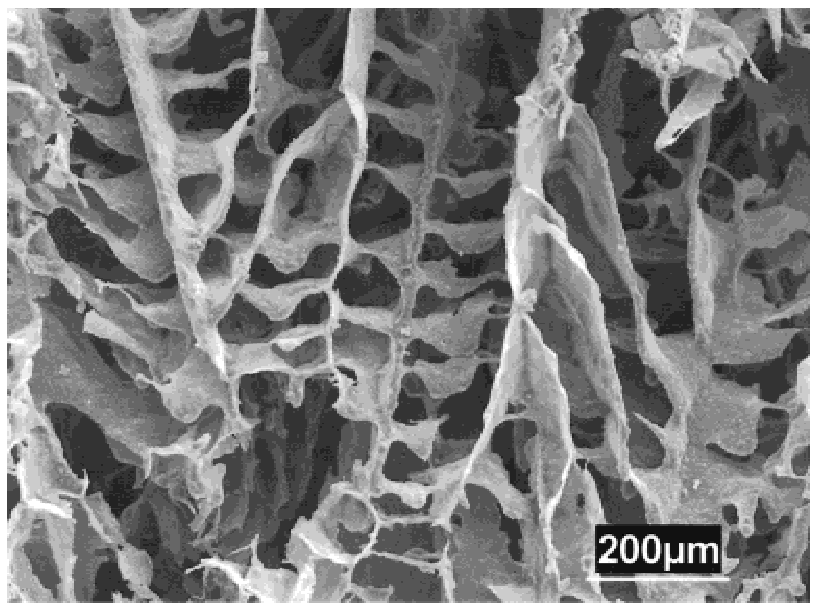

(a)

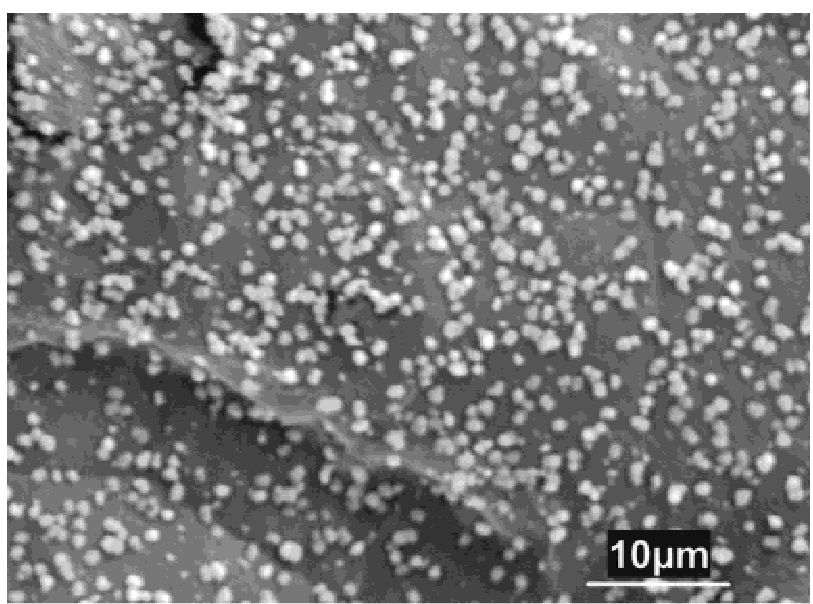

(c)

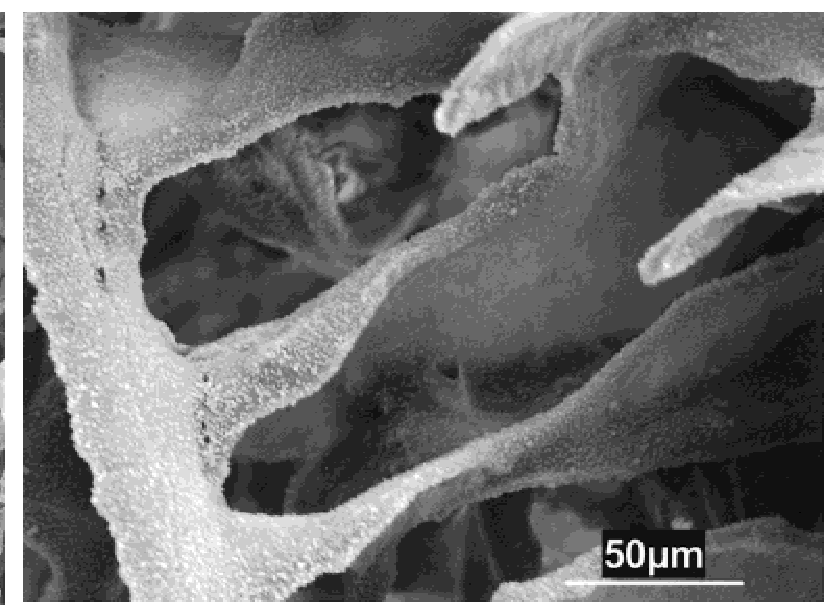

(b)

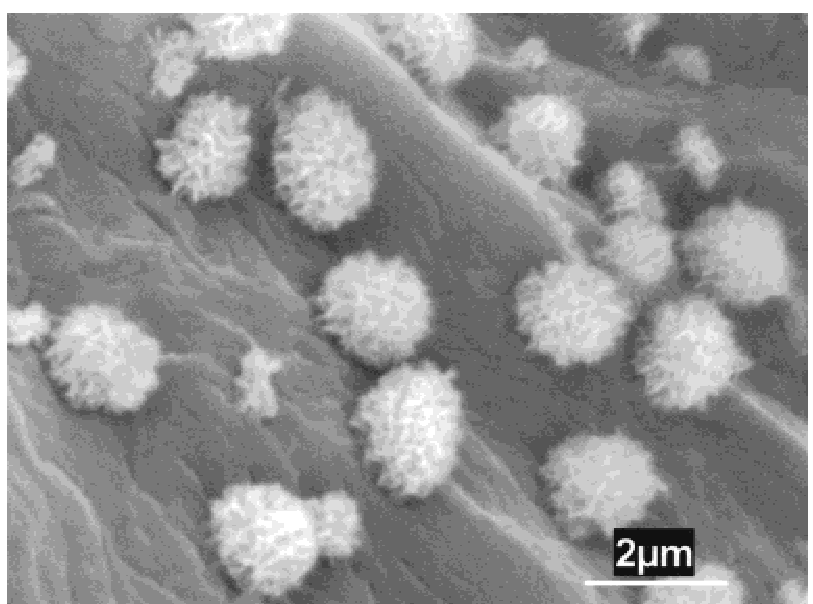

(d)

Figure 1. SEM micrographs of a PLLA foam incubated in SBF for 30 days: original magnifications (a) $\times 100$, (b) $\times 500$, (c) $\times 2000$, and $(d) \times 10,000$.

three samples. The spectra of the formed particles [Fig. $5(\mathrm{a}, \mathrm{b})]$ had a strong absorption band at $873 \mathrm{~cm}^{-1}$ corresponding to the $v_{2}$ vibration mode of carbonate. The broad peak around $1640 \mathrm{~cm}^{-1}$ was assigned to the $\nu_{3}$

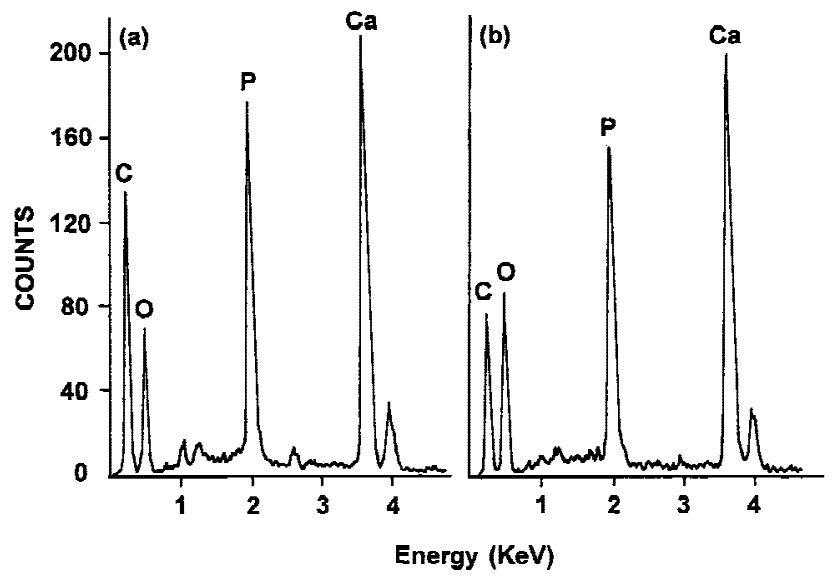

Figure 2. EDS spectra of microparticles from (a) a PLLA foam incubated in SBF for 30 days and (b) a PLLA film incubated in SBF for 15 days. band of carbonate. ${ }^{25,26}$ These carbonate peaks from particles formed from SBF incubation were much higher than those in commercial synthetic HA. Hydroxyl stretch was observed at $3570 \mathrm{~cm}^{-1}$ in the spectrum of commercial synthetic HA [Fig. 5(c)]. However, no evident peak at the same wave number was observed for the particles formed from SBF incubation. The large decrease of the hydroxyl stretch band intensity and the strong carbonate bands of the microparticles formed from SBF indicated the carbonate substitution for $\mathrm{OH}$ in HA. ${ }^{24,26}$ These results suggested that the particles in a PLLA foam or on a PLLA film from SBF incubation were carbonated apatite, which was similar in composition and structure to the natural apatite in human and animal hard tissues. The peaks at $1455 \mathrm{~cm}^{-1}\left(\delta \mathrm{CH}_{3}\right), 1759 \mathrm{~cm}^{-1}\left(v_{\mathrm{C}=\mathrm{O}}\right)$, and peaks ranging from 2870 to $3000 \mathrm{~cm}^{-1}\left(v_{\mathrm{C}-\mathrm{H}}\right)$ in the spectrum [Fig. 5(a)] were attributed to the PLLA, which could be scratched with the apatite particles into the $\mathrm{KBr}$ film prepared for IR analysis.

The variation of the particle number and size in the PLLA foams was achieved by varying the incubation 


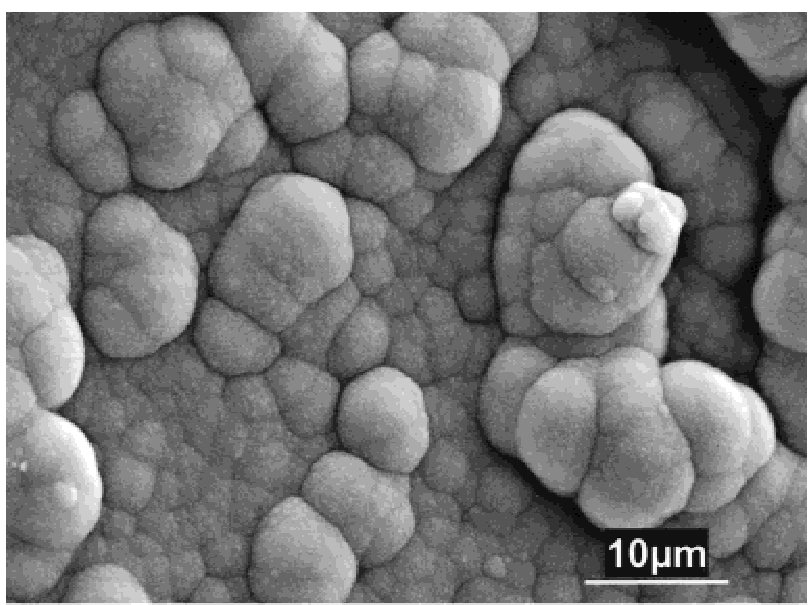

(a)

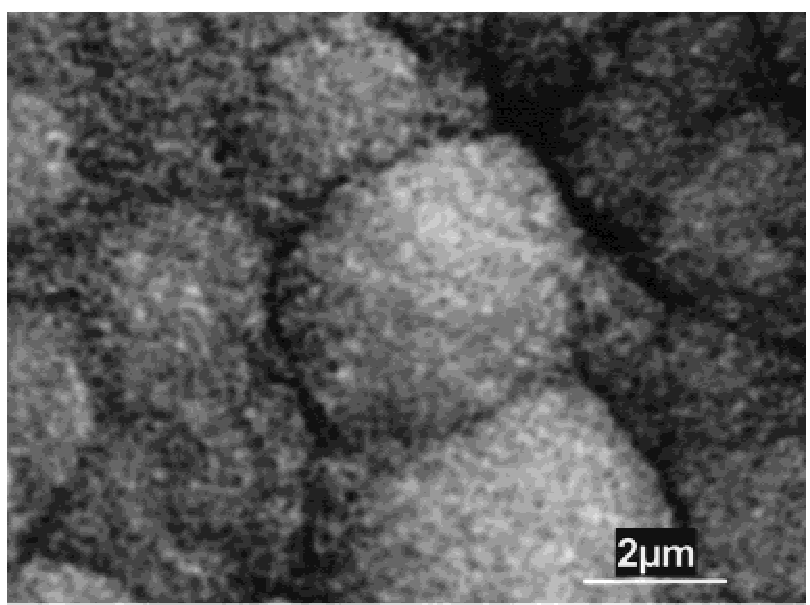

(b)

Figure 3. SEM micrographs of a PLLA film incubated in SBF for 15 days: original magnifications (a) $\times 2000$ and (b) $\times 10,000$.

time in the SBF (Fig. 6). Almost no apatite microparticles were observed on the surfaces of the PLLA pore walls after 3 days of incubation. Scattered and small microparticles were observed after 6 days of incubation. After 15 days of incubation, a large number of apatite microparticles with relatively bigger particle size was observed. EDS analysis also demonstrated that the calcium and phosphate contents increased with incubation time (Fig. 7). As a consequence of particle growth from the nuclei formed at different times, there was a wide size distribution. The average particle diameter, density (number of particles per unit surface area), and total apatite mass increased with incubation time (Fig. 8).

Some PLLA foam samples were immersed in distilled water at $37^{\circ} \mathrm{C}$ for 15 days before incubation in SBF for 15 days. There were significantly more apatite particles formed in the water treated PLLA foams (Fig.

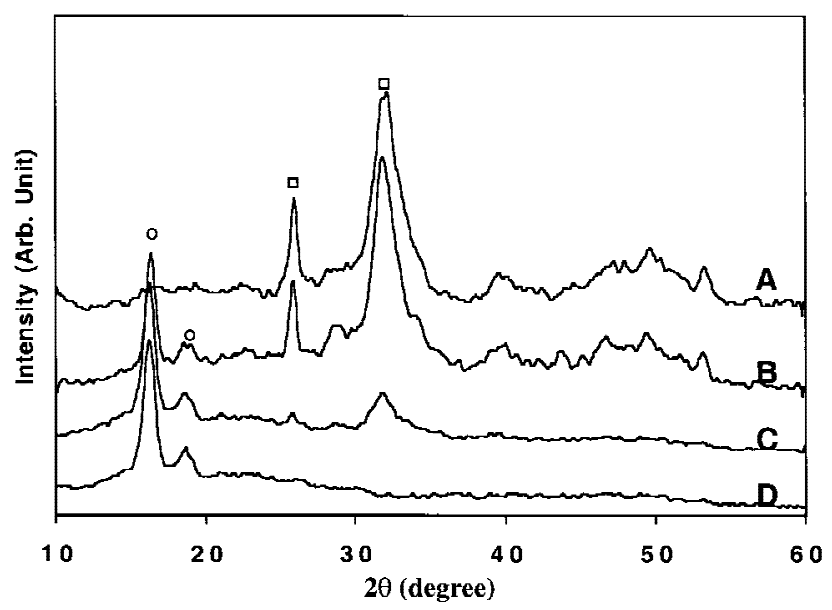

Figure 4. Wide-angle $X$-ray diffraction spectra of (a) powder of apatite obtained from the surface of PLLA films incubated in SBF for 30 days, (b) PLLA foam incubated in SBF for 30 days, (c) PLLA foam incubated in SBF for 15 days, and (d) PLLA foam.
9) than those in the PLLA foams without water treatment [Fig. 6(d)] for the same SBF incubation time (189 \pm 32 vs. $25.3 \pm 6.8$ particles $\left./ 100 \mu \mathrm{m}^{2}, p=1.4 \times 10^{-13}\right)$. However, the average diameter of the particles formed on the water treated foams was significantly smaller $(0.273 \pm 0.084$ vs. $0.837 \pm 0.164 \mu \mathrm{m}, p=3.8 \times$ $\left.10^{-15}\right)$.

The compressive modulus increased with the incubation time in SBF (Fig. 10). After 30 days or longer, the compressive modulus became significantly higher than that of the initial foam $(p<0.05)$. In contrast, the compressive modulus of the foams incubated in a Tris buffer at the same $\mathrm{pH}(7.4)$ and temperature $\left(37^{\circ} \mathrm{C}\right)$ did not change significantly within 60 days of incubation (Fig. 10).

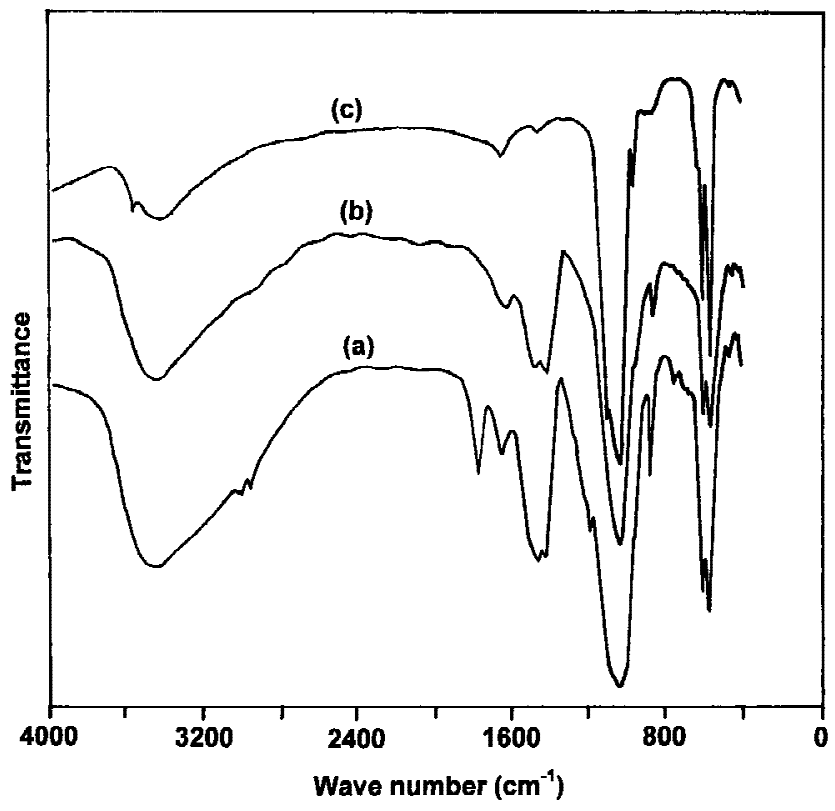

Figure 5. FTIR spectra of a commercial HA; the apatite particles formed from SBF (a) in a PLLA foam, (b) on a PLLA film, or (c) a commercial HA. 


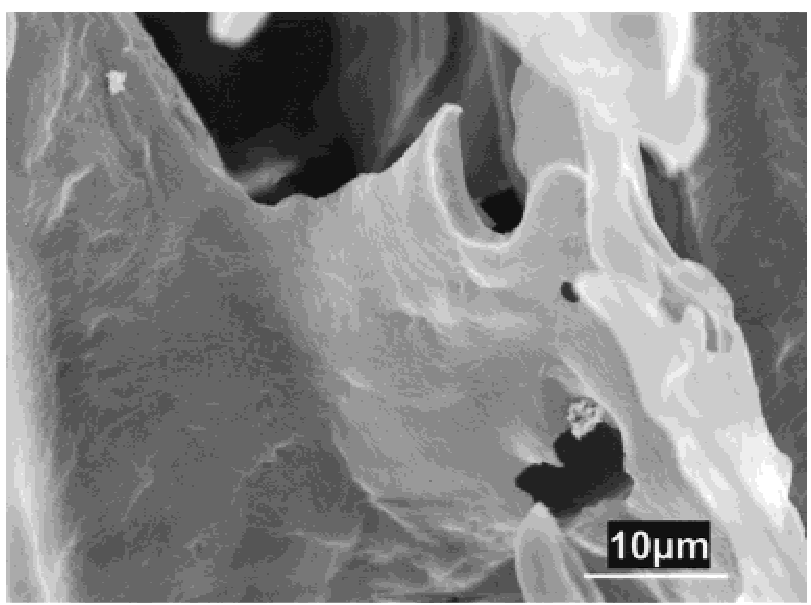

(a)

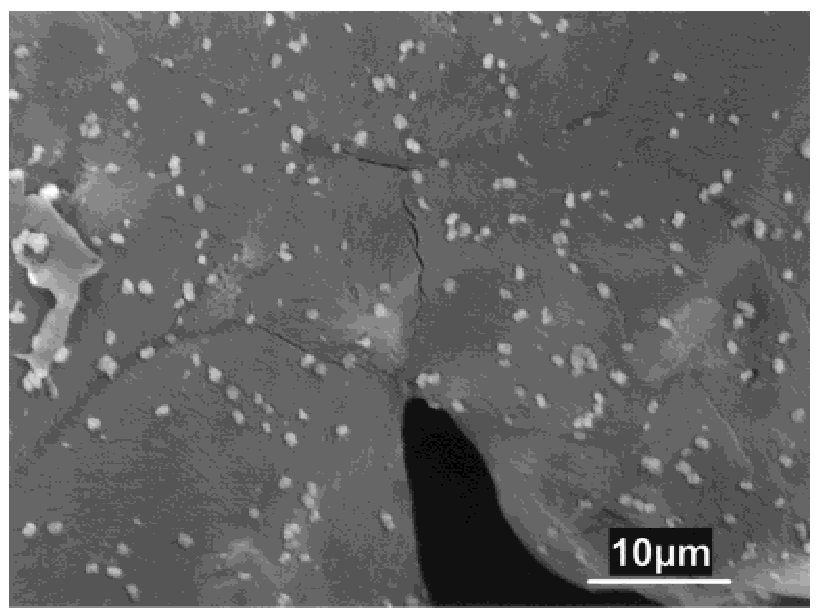

(c)

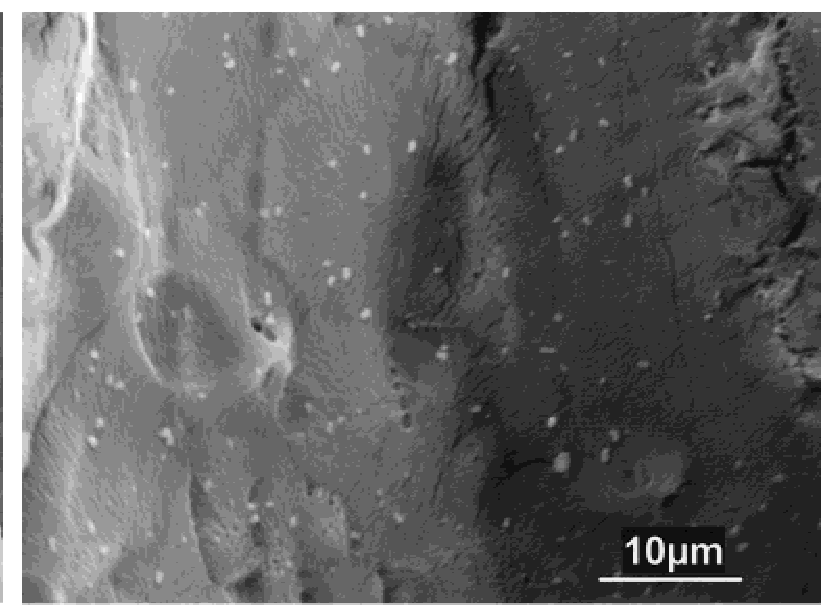

(b)

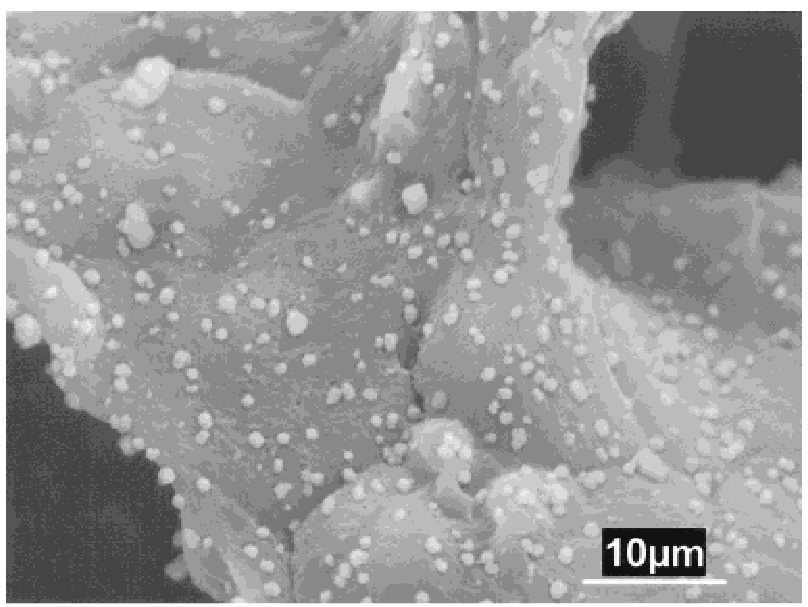

(d)

Figure 6. SEM micrographs of a PLLA foam incubated in SBF for (original magnification $\times 2000)($ a) 3 days, (b) 6 days, (c) 10 days, or (d) 15 days.

\section{DISCUSSION}

A scaffold for tissue engineering should have a high porosity and an appropriate pore size. Various techniques, such as particulate leaching, ${ }^{6,11}$ liquid-liquid phase separation, ${ }^{27,28}$ and others, ${ }^{7,29}$ have been developed to fabricate highly porous scaffolds. In this work, the solid-liquid phase separation of PLLA/dioxane solution and subsequent sublimation of the dioxane have been used to obtain highly porous PLLA foams. The foams have an open pore structure. Varying the concentration of the polymer solution and phase separation temperature can control the pore size ranging from several tens of microns to several hundred mi-

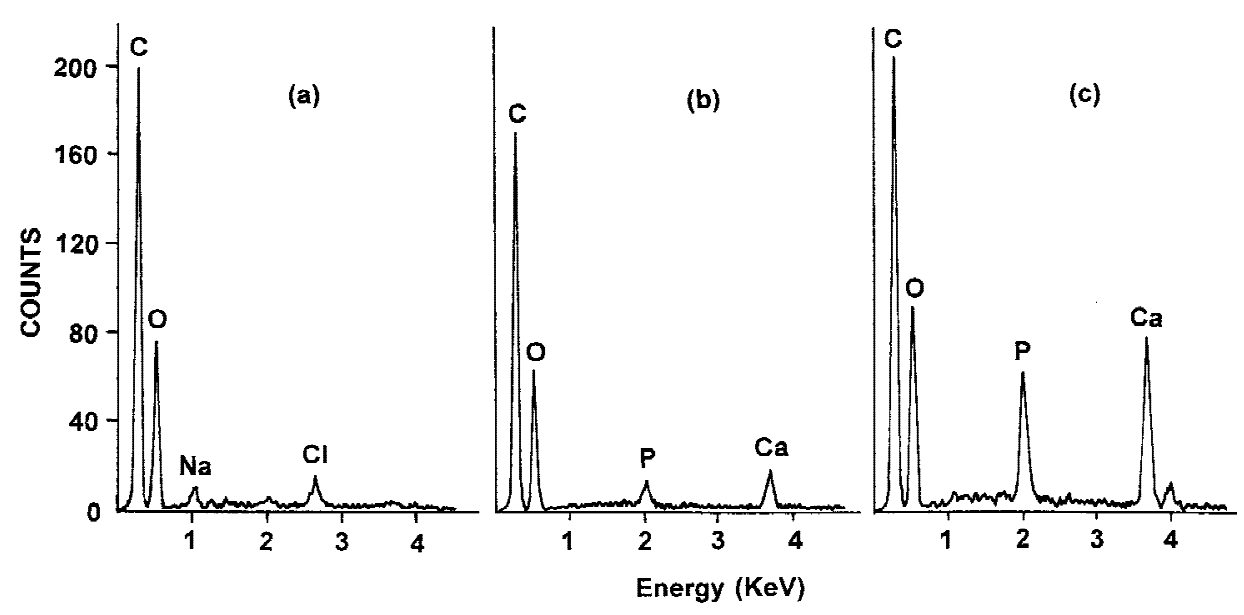

Figure 7. EDS spectra of a PLLA foam incubated in SBF for (a) 3 days, (b) 6 days, or (c) 15 days. 


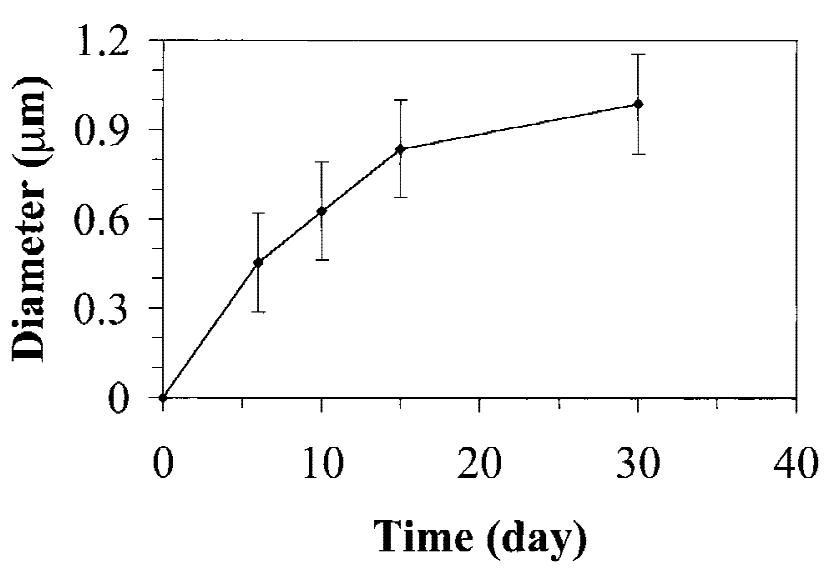

(a)

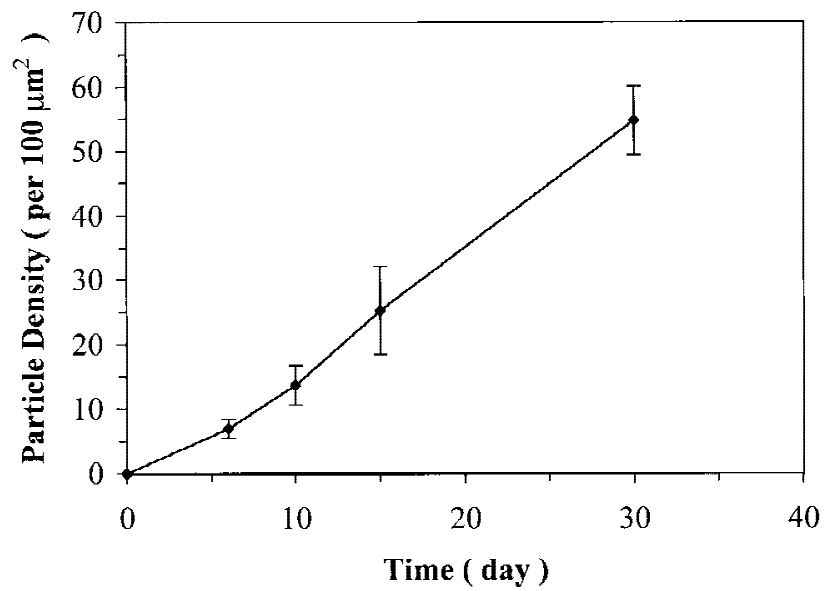

(b)

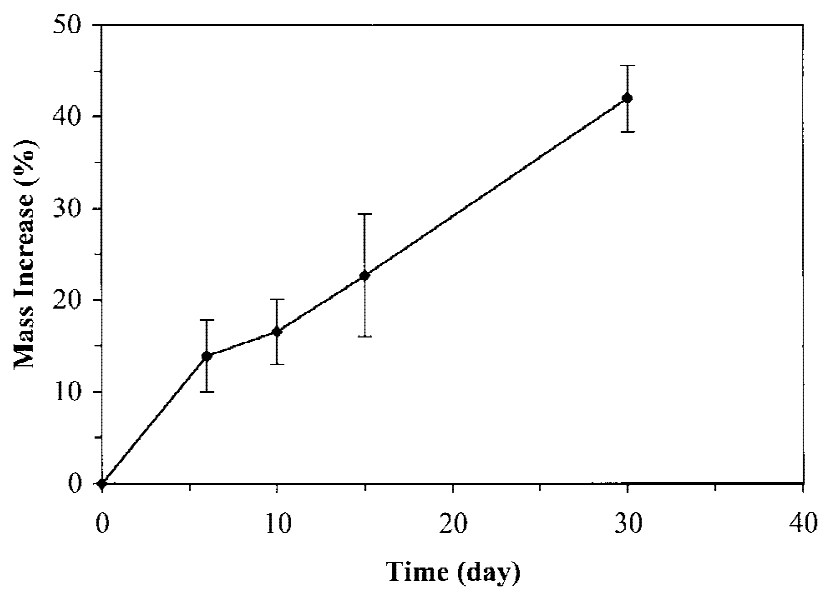

(c)

Figure 8. The average apatite particle (a) diameter, (b) density, and (c) total mass percentage increase over PLLA foam against incubation time in SBF.

crons. ${ }^{5}$ A 5\% PLLA/dioxane solution has been used in this study to prepare PLLA foams for in situ apatite formation because this foam has been well characterized previously to ensure consistency. ${ }^{5}$ However, the polymer concentration (5\%) is not a limiting factor to this new technology.

Bonelike apatite has been reported to form in the body on surfaces of various bioactive materials. ${ }^{13-19,30}$ The bonelike apatite makes the bioactive material favorable to bond to bone chemically. The mechanism of the bonelike apatite formation on $\mathrm{CaO}-\mathrm{SiO}_{2}$ based ceramic surfaces was proposed as follows ${ }^{31,32}$ : the calcium ions dissolved from the ceramics increased the ionic activity product of the apatite in the surrounding body fluid, which was already supersaturated with respect to apatite; and the hydrated silicon surfaces provided favorable sites for apatite nucleation. As a result, a large number of apatite nuclei formed on ceramic surfaces, grew spontaneously, and consumed the calcium and phosphate ions from the surrounding fluid. Based on this mechanism, Kokubo et al. used $\mathrm{CaO}-\mathrm{SiO}_{2}$ glass particles as a nucleation-inducing agent. With the induced nucleation and subsequent incubation in SBF, apatite was grown on several polymer surfaces, such as polyethylene, poly(ethylene terephthalate), poly(methyl methacrylate), Nylon-6, and poly(ether sulfone). ${ }^{33,34}$

To create better scaffolds for bone tissue engineering, porous poly $(\alpha$-hydroxyl acids)/HA composites were developed by phase separation of poly $(\alpha-$ hydroxyl acids)/HA/solvent mixtures and subsequent solvent sublimation in our laboratory. ${ }^{5}$ To our knowledge, this work is the first successful growth of apatite on the inner pore surfaces of a porous material. The apatite particles formed in the PLLA foams incubated in SBF is similar to the bonelike apatite based on SEM, EDS, IR, and XRD analyses. For the apatite formation, the environment that can enhance local calcium and phosphate ion concentrations may be desirable. In the SBF, PLLA could be partially hydrolyzed to generate reasonable numbers of $\mathrm{COOH}$ and $\mathrm{OH}$ groups. The weak acidic group $\mathrm{COOH}$ may dissociate partially in the aqueous solution of SBF ( $\mathrm{pH}$ 7.4) at $37^{\circ} \mathrm{C}$, leaving the polymer surface negatively charged. The calcium and phosphate ions may be accumulated by $\mathrm{COO}^{-}, \mathrm{COOH}$, and $\mathrm{OH}$ groups through electrostatic force and hydrogen bonding. The local increase of supersaturation of calcium and phosphate ions makes the nucleation of apatite possible. The hydrolysis of the PLLA is a slow process and the degree of the hydrolysis is time dependent. With increasing incubation time, the $\mathrm{COOH}$ and $\mathrm{OH}$ groups increase, which leads to the increased apatite nucleation rate.

In order to test whether the polymer hydrolysis is important in the apatite nucleation, PLLA foam samples were immersed in distilled water at $37^{\circ} \mathrm{C}$ for 15 days before incubation in SBF. The number of apatite particles formed in the water treated PLLA foams was significantly larger (189 vs. $\left.29.3 / 100 \mu \mathrm{m}^{2}\right)$ while the average particle diameter was significantly smaller $(0.273$ vs. $0.837 \mu \mathrm{m})$ than those in the PLA foams without water treatment for the same SBF incubation time. The hydrated groups such as $\mathrm{COOH}$ and $\mathrm{OH}$ from the PLLA hydrolysis may contribute to the higher apatite 


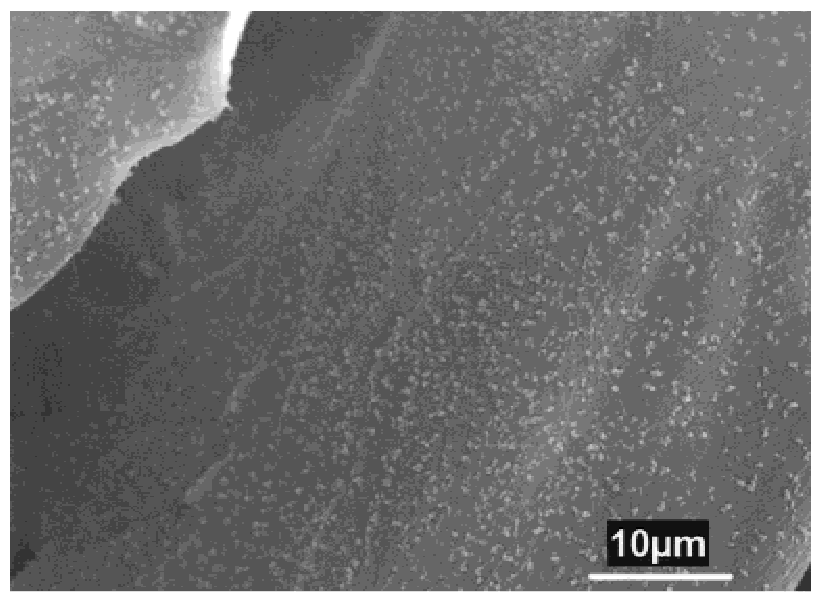

(a)

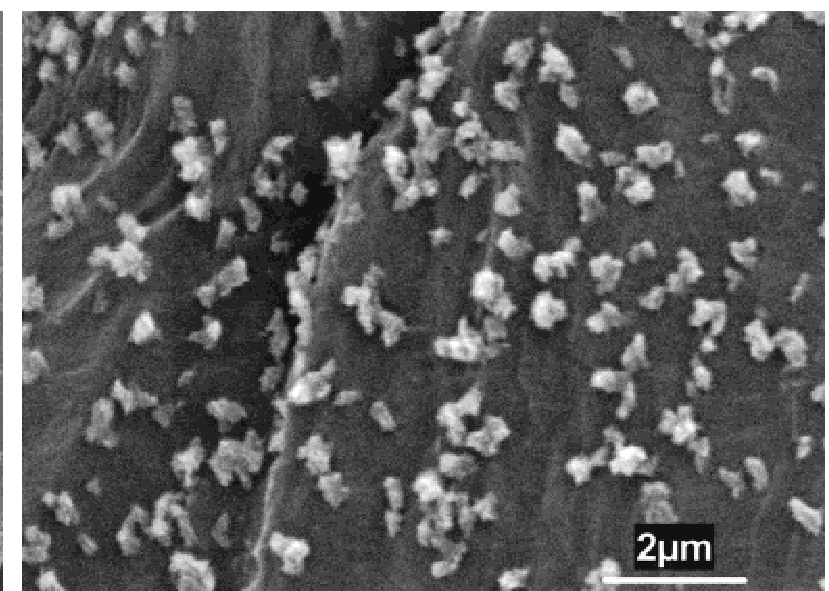

(b)

Figure 9. SEM micrographs of a PLLA foam immersed in $\mathrm{H}_{2} \mathrm{O}$ (at $37^{\circ} \mathrm{C}$ ) for 15 days and then incubated in SBF for 15 days: original magnifications (a) $\times 2000$ and (b) $\times 10,000$.

nucleation rate in the water treated PLLA foams. The higher number of initial nucleation sites may compete with each other for the calcium and phosphate ions, thus leading to the smaller average size. This result indicates that the hydrolysis of PLLA may have played an important role during the apatite formation in the PLLA foams, which corroborates our hypothesis.

The solid PLLA films were completely covered with apatite particles in a relatively short incubation time. Much larger apatite particles were formed on the PLLA films than in PLLA foams with the same incubation time, which was presumably due to a much smaller surface area on the solid films, leading to a higher degree of supersaturation with respect to the small number of nucleation sites and a fast apatite particle size growth.

The compressive modulus of the PLLA/apatite foams was higher than that of the initial PLLA foam. This indicated that the apatite particles enhanced the

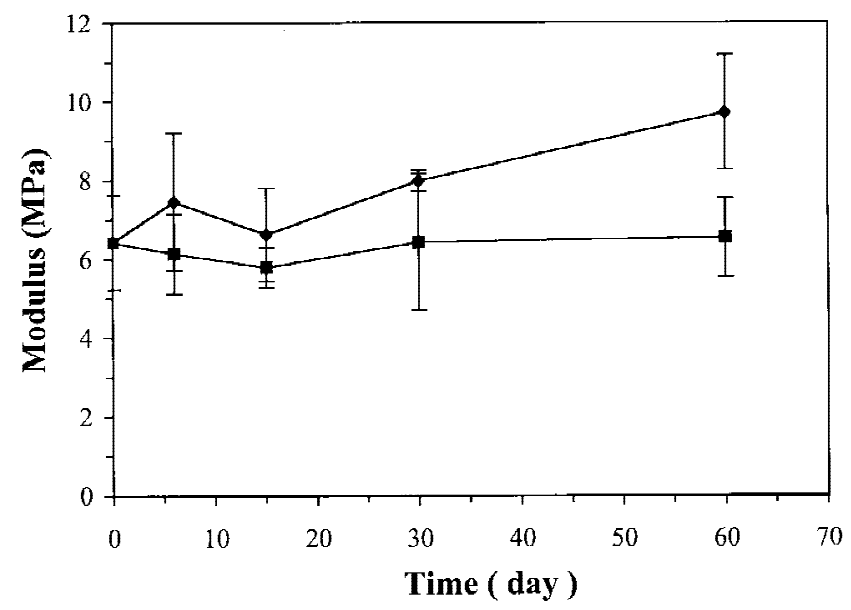

Figure 10. Compressive modulus against incubation time at $37^{\circ} \mathrm{C}$ in $(\diamond)$ the SBF and (ם) a Tris buffer at $\mathrm{pH} 7.4$. mechanical properties of the foams. The compressive modulus of the foams incubated in a Tris buffer at the same conditions within 60 days had no significant change compared to the initial foam. It seems that the molecular weight decrease within this time frame was not large enough to cause mechanical property deterioration. This was presumably due to the slow hydrolysis rate of the hydrophobic PLLA.

This work demonstrated how the biomimetic process of in situ apatite formation from an SBF can be used to fabricate porous biodegradable polymer/ apatite composites. Although the PLLA foams were created with a solid-liquid phase separation technique in this work, the method could be utilized to grow apatite for other porous polymeric or nonpolymeric materials as long as they have an open pore structure to allow SBF penetration.

\section{CONCLUSIONS}

Highly porous PLLA foams with a ladderlike porous structure were prepared from phase separation of the polymer solutions and subsequent solvent sublimation. New porous PLLA/apatite composites were created by incubating the polymer foams in the SBF. A large number of apatite microparticles was formed in situ on the surfaces of pore walls throughout the PLLA foams. Based on SEM, EDS, XRD, and FTIR analyses, the apatite particles were similar to the apatite in natural bone. These apatite particles were characteristic porous spheres assembled with small flakes. The apatite particles were formed through a nucleation phase and a growth phase. The particle number and size were determined by several factors such as incubation time, ionic concentration of the SBF, water treatment, and the polymer surface area. The compressive modulus 
increased with incubation time in the SBF. The excellent bone-bonding property of the bonelike apatite may provide a good environment for the attachment and growth of osteoblasts and osteoprogenitor cells.

\section{References}

1. Langer R, Vacanti J. Tissue engineering. Science 1993;260 (5110):920-926.

2. Vacanti CA, Vacanti JP. Bone and cartilage reconstruction. In: Lanza RP, Langer R, Chick WL, editors. Principles of tissue engineering. Austin, TX: R. G. Landes Company; 1997. p 619631.

3. Crane G, Ishaug S, Mikos A. Bone tissue engineering. Nat Med 1995;1:1322-1324.

4. Vacanti C, Vacanti J. Bone and cartilage reconstruction with tissue engineering approaches. Otolaryngol Clin North Am 1994;27(1):263-276.

5. Zhang R, Ma PX. Poly( $\alpha$-hydroxy acids)/hydroxyapatite porous composites for bone tissue engineering. I. Preparation and morphology. J Biomed Mater Res 1999;44:446-455.

6. Ma PX, Langer R. Fabrication of biodegradable polymer foams for cell transplantation and tissue engineering. In: Yarmush M, Morgan J, editors. Tissue engineering methods and protocols. Totowa, NJ: Humana Press Inc.; 1998.

7. Ma PX, Langer R. Degradation, structure and properties of fibrous nonwoven poly(glycolic acid) scaffolds for tissue engineering. In: Mikos AG, Leong KW, Yaszemski MJ, Tamada JA, Radomsky ML, editors. Polymers in medicine and pharmacy. Pittsburgh, PA: MRS; 1995. p 99-104.

8. Ma PX, Schloo B, Mooney D, Langer R. Development of biomechanical properties and morphogenesis of in vitro tissue engineered cartilage. J Biomed Mater Res 1995;29:1587-1595.

9. Ma PX, Shin'oka T, Zhou T, Shum-Tim D, Lien J, Vacanti JP, Mayer J, Langer R. Biodegradable woven/nonwoven composite scaffolds for pulmonary artery engineering in an juvenile lamb model. Trans Soc Biomater 1997;20:295.

10. Ma PX, Langer R. Morphology and mechanical function of long-term in vitro engineered cartilage. J Biomed Mater Res 1999;44:217-221.

11. Mikos AG, Thorsen AJ, Czerwonka LA, Bao Y, Langer R, Winslow DN, Vacanti JP. Preparation and characterization of poly(L-lactic acid) foams. Polymer 1994;35:1068-1077.

12. Jarcho M. Retrospective analysis of hydroxyapatite development for oral implant applications. Dent Clin North Am 1992; 36:19-26.

13. Kokubo T, Shigematsu M, Nagashima Y, Tashiro M, Yamamuro T, Higashi S. Apatite- and wollastonite-containing glassceramics for prosthetic application. Bull Inst Chem Res Kyoto Univ 1982;60:260-268.

14. Hench LL. Bioactive ceramics. Ann New York Acad Sci 1988; 523:54-71.

15. Kitsugi T, Yamamuro T, Nakamura T, Kokubo T. Bone bonding behavior of $\mathrm{MgO}-\mathrm{CaO}-\mathrm{SiO}_{2}-\mathrm{P}_{2} \mathrm{O}_{5}-\mathrm{CaF}_{2}$ glass (mother glass of AW-glass-ceramics). Biomed Mater Res 1989;23:631648.

16. Li P, Nakanishi K, Kokubo T, de Groot K. Induction and morphology of hydroxyapatite, precipitated from metastable simulated body fluids on sol-gel prepared silica. Biomaterials 1993; 14:963-968.
17. Kitsugi $\mathrm{T}$, Yamamuro T, Nakamura T, Kokubo T. The bonding of glass ceramics to bone. Int Orthop (SICOT) 1989;13:199-206.

18. van Blitterswijk CA, Bakker D, Leenders H, Blink Jvd, Hesseling SC, Bovell YP, Radder AM, Sakkers RJ, Gaillard ML, Heinze PH, Beumer GJ. Interfacial reactions leading to bone bonding with $\mathrm{PEO} / \mathrm{PBT}$ copolymers (Polyactive). In: Ducheyne P, Kokubo T, van Blitterswijk CA, editors. Bonebonding biomaterials. Leiderdrop: Reed Healthcare Communication; 1992. p 13-30.

19. Li P, Bakker D, van Blitterswijk CA. The bone-bonding polymer Polyactive 80/20 induces hydroxycarbonate apatite formation in vitro. J Biomed Mater Res 1997;34:79-86.

20. Kokubo T, Kushitani H, Sakka S, Kitsugi T, Yamamuro T. Solutions able to reproduce in vivo surface-structure changes in bioactive glass-ceramic A-W. J Biomed Mater Res 1990;24:721734.

21. Aoki H. Science and medical applications of hydroxyapatite. Tokyo: Jaas; 1991. p vii, xv, 214.

22. Brizzolara D, Cantow HJ, Diederichs K, Keller E, Domb AJ. Mechanism of the stereocomplex formation between enantiomeric poly(lactide)s. Macromolecules 1996;29:191-197.

23. Fowler BO. Infrared study of apatite. Inorg Chem 1974;13:194214.

24. Rehman I, Bonfield W. Characterization of hydroxyapatite and carbonated apatite by photo acoustic FTIR spectroscopy. J Mater Sci Mater Med 1997;8:1-4.

25. El Feki H, Rey C, Vignoles M. Carbonate ions in apatite, infrared investigation in $v_{r} \mathrm{CO}_{3}$ domain. Calcif Tissue Int 1991;49: 269-274.

26. Elliott JC, Holcomb DW, Young RA. Infrared determination of the degree of substitution of hydroxyl by carbonate ions in human dental enamel. Calcif Tissue Int 1985;37:372-375.

27. Schugens C, Maquet V, Grandfils C, Jerome R, Teyssie P. Polylactide macroporous biodegradable implants for cell transplantation. II. Preparation of polylactide foams by liquid-liquid phase separation. J Biomed Mater Res 1996;30:449-461.

28. Lo H, Ponticiello MS, Leong KW. Fabrication of controlled release biodegradable foams by phase separation. Tissue Eng 1995;1:15-28.

29. Wintermantel E, Mayer J, Blum J, Eckert KL, Luscher P, Mathey M. Tissue engineering scaffolds using superstructures. Biomaterials 1996;17:83-91.

30. Jarcho M, Kay JF, Gumaer KI, Doremus RH, Drobeck HP. Tissue, cellular and subcellular events at a bone-ceramic hydroxylapatite interface. J Bioeng 1977;1:79-92.

31. Ohtsuki C, Kokubo T, Yamamuro T. Mechanism of apatite formation on $\mathrm{CaO}-\mathrm{SiO}_{2}-\mathrm{P}_{2} \mathrm{O}_{5}$ glasses in a simulated body fluid. J Non-Cryst Solids 1992;143:84-92.

32. Li P, Ohtsuki C, Kokubo T, Nakanishi K, Soga N, Nakamura T, Yamamuro T. Apatite formation induced by silica gel in a simulated body fluid. J Am Ceram Soc 1992;75:2094-2097.

33. Kokubo T, Hata K, Nakamura T, Yamamuro T. Apatite formation on ceramics, metals and polymers induced by a $\mathrm{CaO}-\mathrm{SiO}_{2}$-based glass in a simulated body fluid. In: Bonfield W, Hastings GW, Tunner KE, editors. Bioceramics. Guiford, UK: Butterworth-Heinemann; 1991. p 113-120.

34. Tanahashi M, Yao T, Kokubo T, Minoda M, Miyamoto T, Nakamura T, Yamamuro T. Apatite coating on organic polymers by a biomimetic process. J Am Ceram Soc 1994;77:2805-2808. 